\title{
Pseudo-acne fulminans associated with oral isotretinoin*
}

\author{
Luciana Rosa Grando ${ }^{1}$
}

Oriete Gerin Leite ${ }^{2}$

Tania Ferreira Cestari ${ }^{1}$

DOI: http://dx.doi.org/10.1590/abd1806-4841.20143024

\begin{abstract}
Acne fulminans is a rare and serious condition characterized by the sudden onset of nodular and ulcerative acne lesions associated with systemic symptoms. It has been recognized a subset of patients with a sudden worsening of acne, often during treatment with oral isotretinoin, but without the strong presence of systemic involvement. Recognized by some authors as "pseudo-acne fulminans" or " acne fulminans sine fulminans," we report a case with these features in order to draw attention to the recognition and early management of this manifestation.
\end{abstract}

Keywords: Acne vulgaris; Acneiform eruptions; Isotretinoin; Prednisone; Propionibacterium acnes

\section{INTRODUCTION}

Acne fulminans (AF) was described for the first time in 1959. ${ }^{1}$ It is a rare condition that affects mainly male young individuals and is characterized by the abrupt onset of nodular acneic and ulcerative lesions, which may be accompanied by fever, arthralgias, myalgias, and osteolytic lesions. ${ }^{2}$ The etiopathogenesis of AF is not completely clarified and infectious, genetic, hormonal and immunological mechanisms have already been proposed. There are cases related to the use of oral isotretinoin, probably due to exaggerated hypersensitivity reactions of type III and IV, after massive contact with Propionibacterium acnes antigens favored by the fragility of the pilosebaceous epithelium induced by this drug. ${ }^{3,4}$ Another theory is an altered neutrophil function, genetically determined, with hyperreactivity to inflammatory mediators and decreased phagocytosis of $P$. acnes which, in an augmented proportion, would explain even the disease escapes at the start of therapy with oral isotretinoin. ${ }^{5}$

\section{CASE REPORT}

Male patient, 16-year-old, presented a clinical picture of papulous-pustular acne, with some nodular and keloid scattered lesions on the trunk. Due to no response to treatment with adapalene $0.1 \%$ and tetracycline $1000 \mathrm{mg} /$ day, $0.6 \mathrm{mg} / \mathrm{kg} /$ day of oral isotretinoin was prescribed. By the end of the first month, improvement of facial lesions was observed, however nodular and ulcerated lesions appeared on the trunk (Figures 1A, 1B and 1C). There was no report of fever, arthralgias or other systemic symptoms and the laboratory exams remained within normal parameters. Since there was no improvement until the third month of treatment, it was opted to associate prednisone $0.6 \mathrm{mg} / \mathrm{kg} /$ day and oral isotretinoin reduced to $0.3 \mathrm{mg} / \mathrm{Kg} /$ day, obtaining the control of lesions in the course of 3 months with this therapeutical regimen. By the end of a 6-month period the total $7200 \mathrm{mg}$ $(120 \mathrm{mg} / \mathrm{kg})$ dose of isotretinoin was reached and corticotherapy was gradually reduced over a 2-month period. There was global improvement of the acneic clinical picture, with persistence of cicatricial lesions. The patient had a body weight increase of $15 \mathrm{~kg}$, which cannot be totally attributed to the use of oral prednisone (Figures 2A, 2B and 2C).

\section{DISCUSSION}

The occurrence of AF is a rare event, although described in several articles in the worldwide literature. Without clear etiopathogenesis, it is characterized by a clinical picture of severe acute febrile ulcerative acne and may be related to several triggering factors. Five criteria for the diagnosis of $\mathrm{AF}$ were proposed by Burns and Colville: 1) sudden onset of lesions; 2) seve-

\footnotetext{
Received on 31.07.2013.

Approved by the Advisory Board and accepted for publication on 23.08.2013.

Work performed at a private clinic - Porto Alegre (RS), Brazil.

Financial Support: None

Conflict of Interests: None.

Universidade Federal do Rio Grande do Sul (UFRGS) - Porto Alegre (RS), Brazil.

Private practice - Campinas (SP), Brazil.

C2014 by Anais Brasileiros de Dermatologia
} 

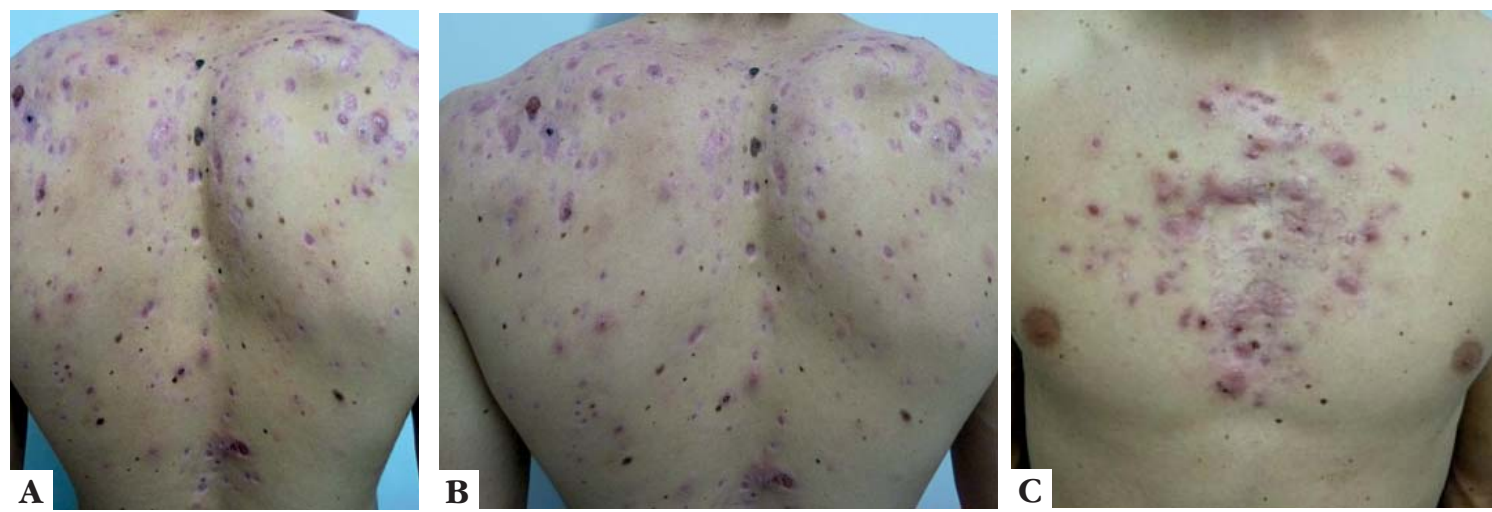

FIGURE 1: The end of the first month of treatment with oral isotretinoin. A. Onset of nodular and ulcerated lesions on the back; B. Zoomedin view of the back; C. Nodular and ulcerative lesions on the front of thorax
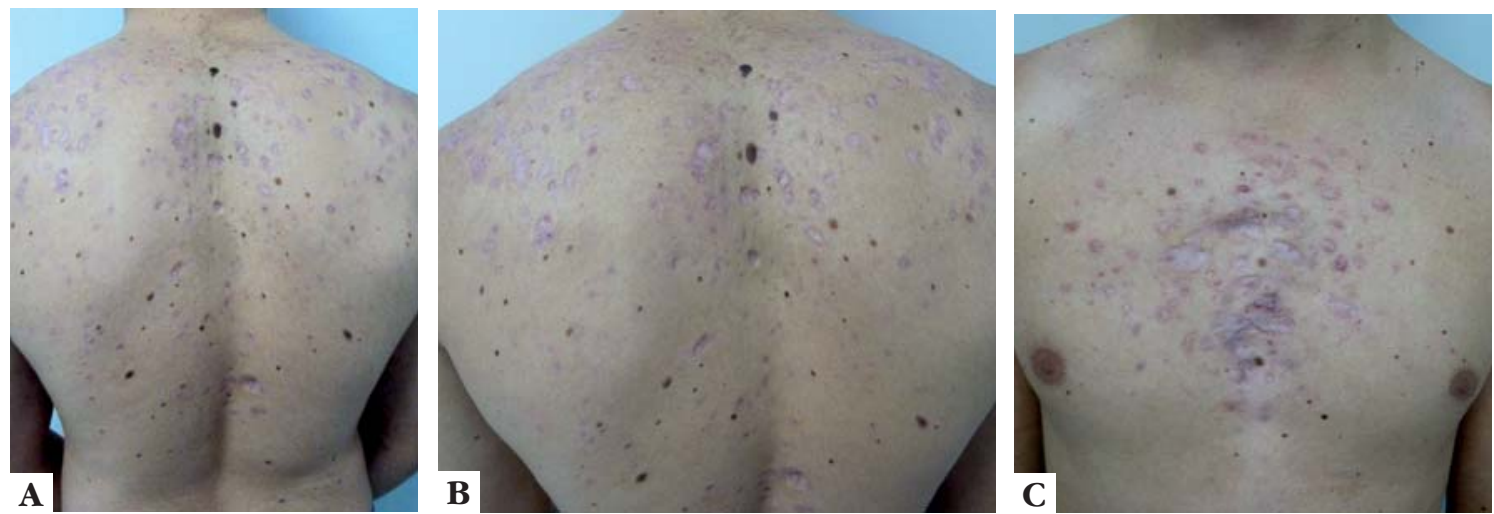

Figure 2: A. View of the back, by the end of treatment with isotretinoin at the accumulated dose of $7200 \mathrm{mg}(120 \mathrm{mg} / \mathrm{Kg})$ and $5 \mathrm{months}$ of corticotherapy with prednisone $(0.6 \mathrm{mg} / \mathrm{kg}$ for 3 months, and gradual reduction for 2 months); B. Zoomed-in view of the back, by the end of treatment with isotretinoin associated to oral prednisone; $\mathbf{C}$. View of front of thorax, by the end of treatment with isotretinoin and oral prednisone

re ulcerated acne which determine cicatricial lesions; 3) systemic symptoms like fever and polyarthralgia; 4) absence of response to antibiotics; 5) favorable response to corticosteroid therapy. ${ }^{1}$

The manifestations of sudden worsening of acne without systemic symptoms characterizes a subgroup called "pseudo-acne fulminans" or "acne fulminans sine fulminans", described in few scientific reports. These patients present cutaneous lesions with severity comparable to AF, however without the clinical-laboratory systemic findings.

The most accepted ethiology for the onset of pseudo-acne fulminans would be a hypersensitivity reaction to bacterial agents of $P$. acnes released during treatment with oral isotretinoin. It is speculated that changes in innate immunity determine deviations in the production of interleukins and exacerbated neutrophilic function, generating necrotizing ulcerative skin lesions. ${ }^{6}$

Thomson e Cunliffe ${ }^{7}$ reported 14 cases of acne with severity comparable to AF but without systemic involvement. The majority of patients were male (78\%), with mean age of 17 and had moderate acne history. A common characteristic to virtually all patients was the presence of macro-comedones and use of oral isotretinoin before the onset of the clinical picture. Patients were treated with a combination of low isotretinoin and prednisolone dose with excellent response.

It is probable that the patients with severe disease of sudden onset present a similar ethiology with and without the presence of systemic symptoms. The behavior of the disease and, therefore, the handling of it also seem to be similar. ${ }^{7}$ The use of corticotherapy to control acne fulminans is acknowledged, associated or not with low doses of oral isotretinoin. ${ }^{8,9}$ The best results were obtained with the association of corticotherapy and oral isotretinoin. ${ }^{10}$ Paradoxically, the same drug which may trigger AF or "pseudo-fulminans" is part of patient management, and should be maintained in reduced doses until the stabilization of the symptoms, as well as possibly increased later 
according to the clinical response of the patient. ${ }^{8}$

Since the routine implementation of a protocol that combines the use of oral isotretinoin and corticoids simultaneously from the start of severe inflammatory acne treatment, Kaminsky et. al did not observe this effect anymore, concluding that "pseudo-acne fulminans" is a preventable complication in oral isotretinoin treatment ${ }^{10}$. In cases where manifestations occur during treatment with the retinoid, the authors propose early introduction of prednisone at a dose of 0.5 a $1.0 \mathrm{mg} / \mathrm{kg} /$ day for 4 to 6 weeks, gradually and slowly decreasing later on. Oral isotretinoin can be maintained at a dose of $0.5 \mathrm{mg} / \mathrm{kg} /$ day, increasing it according to reduction of corticosteroid. ${ }^{10}$

\section{REFERENCES}

1. Burns RE, Colville JM. Acne conglobata with septicemia. Arch Dermatol. 1959;79:361-3

2. Karvonen SL. Acne fulminans: report of clinical findings and treatment of twentyfour patients. J Am Acad Dermatol. 1993;28:572-9.

3. Mehrany K, Kist JM, Weenig RH, Witman PM. Acne fulminans. Int J Dermatol. 2005;44:132-3

4. Zaba R, Schwartz R, Jarmuda S, Czarnecka-Operacz M, Silny W. Acne fulminans: explosive systemic form of acne. J Eur Acad Dermatol Venereol. 2011;25:501-7.

5. Perkins W, Crocket KV, Hodgins MB, Mackie RM, Lackie JM. The effect of treatment with 13-cis-retinoic acid on the metabolic burst of peripheral blood neutrophils from patients with acne. Br J Dermatol. 1991;124:429-32.

6. Moreno GJ, Feliu MM, Camacho F. Pseudo-acne fulminans caused by isotretinoin. Med Cutan Ibero Lat Am. 1988;16:59-60.

7. Thomson KF, Cunliffe WJ. Acne fulminans "sine fulminans". Clin Exp Dermatol. 2000;25:299-301.

8. Seukeran DC, Cunliffe WJ. The treatment of acne fulminans: a review of 25 cases. Br J Dermatol. 1999;141:307-9.

9. Mehra T, Borelli C, Burgdorf W, Röcken M, Schaller M. Treatment of severe acne with low-dose isotretinoin. Acta Derm Venereol. 2012;92:247-8.

10. Kaminsky A. Less common methods to treat acne. Dermatology. 2003;206:68-73.
The introduction of systemic antibiotics is necessary when secondary infections are present and must be prescribed according to the antibiogram. ${ }^{4}$ It is imperative to emphasize the contraindication of prescribing tetracyclines and their derivatives in association with isotretinoin, due to the risk of developing intracranial hypertension.

It is important to recognize this sub-group of patients, who have severe acne of sudden onset without systemic symptoms, since its management must be promptly modified in order to avoid deforming scars. With the evidences currently available, it is also proposed, as a way to prevent pseudo-acne fulminans, to start previous treatment of macro-comedones and begin therapy with isotretinoin at low doses, associated or not with oral corticoids until total remission of symptoms. ${ }^{5,7-10}$
MAILING ADDRESS:

Luciana Rosa Grando

Av. Luiz Manoel Gonzaga, 23

90470-280 - Porto Alegre - RS

Brazil

E-mail: lucianarosa920@hotmail.com

How to cite this article: Grando LR, Leite OG, Cestari TF. Pseudo-acne fulminans associated with oral isotretinoin. An Bras Dermatol. 2014;89(4):657-9. 